\title{
What caused the extreme CO concentrations during the 2017 high-pollution episode in India?
}

\author{
Iris N. Dekker ${ }^{1,2}$, Sander Houweling ${ }^{1,3}$, Sudhanshu Pandey ${ }^{1,2,3}$, Maarten Krol ${ }^{1,2,4}$, Thomas Röckmann ${ }^{2}$, \\ Tobias Borsdorff ${ }^{1}$, Jochen Landgraf ${ }^{1}$, and Ilse Aben ${ }^{1}$ \\ ${ }^{1}$ SRON Netherlands Institute for Space Research, Utrecht, 3584 CC, the Netherlands \\ ${ }^{2}$ Institute for Marine and Atmospheric Research Utrecht, Utrecht University, Utrecht, 3584 CA, the Netherlands \\ ${ }^{3}$ Department of Earth Sciences, Vrije Universiteit Amsterdam, Amsterdam, $1081 \mathrm{HV}$, the Netherlands \\ ${ }^{4}$ Department of Meteorology and Air Quality, Wageningen University and Research Centre, \\ Wageningen, 6708 PB, the Netherlands
}

Correspondence: Iris N. Dekker (i.dekker@sron.nl)

Received: 4 October 2018 - Discussion started: 13 November 2018

Revised: 20 February 2019 - Accepted: 25 February 2019 - Published: 19 March 2019

\begin{abstract}
The TROPOspheric Monitoring Instrument (TROPOMI), launched 13 October 2017, has been measuring carbon monoxide (CO) concentrations in the Earth's atmosphere since early November 2017. In the first measurements, TROPOMI was able to measure $\mathrm{CO}$ concentrations of the high-pollution event in India of November 2017. In this paper, we studied the extent of the pollution in India, comparing the TROPOMI CO with modeled data from the Weather Research and Forecasting model (WRF) to identify the most important sources contributing to the high pollution, both at ground level and in the total column. We investigated the period 11-19 November 2017. We found that residential and commercial combustion was a much more important source of $\mathrm{CO}$ pollution than the post-monsoon crop burning during this period, which is in contrast to what media suggested and some studies on aerosol emissions found. Also, the high pollution was not limited to Delhi and its direct neighborhood but the accumulation of pollution extended over the whole Indo-Gangetic Plain (IGP) due to the unfavorable weather conditions in combination with extensive emissions. From the TROPOMI data and WRF simulations, we observed a buildup of $\mathrm{CO}$ during 11-14 November and a decline in $\mathrm{CO}$ after 15 November. The meteorological conditions, characterized by low wind speeds and shallow atmospheric boundary layers, were most likely the primary explanation for the temporal accumulation and subsequent dispersion of regionally emitted $\mathrm{CO}$ in the atmosphere. This emphasizes
\end{abstract}

the important role of atmospheric dynamics in determining the air quality conditions at ground level and in the total column. Due to its rapidly growing population and economy, India is expected to encounter similar pollution events more often in future post-monsoon and winter seasons unless significant policy measures are taken to reduce residential and commercial emissions.

\section{Introduction}

During November 2017, India encountered an extreme pollution episode. Various ground-level measurement stations reported Air Quality Index (AQI; http://aqicn.org/, last access: 5 November 2018) values of 999, i.e., far above the standard scale that is limited to 500. These high AQIs were caused by high concentrations of several pollutants, but most importantly particulate matter $\left(\mathrm{PM}_{10}\right.$ and $\left.\mathrm{PM}_{2.5}\right)$, with reported values of $>700 \mu \mathrm{g} \mathrm{m}^{-3} \mathrm{PM}_{2.5}$ and carbon monoxide with values of up to $10 \mathrm{mg} \mathrm{m}^{-3}$ several days in a row. Most of this pollution was found over the Indian part of the IndoGangetic Plain (hereafter called IGP), a highly populated region in the north of India near the Himalayas, including the cities of Delhi, Agra, Kanpur, Lucknow, Patna and Kolkata. Heavy air pollution is an annual recurring problem in this region, especially during the post-monsoon and winter months (Cusworth et al., 2018; Vadrevu et al., 2011; Girach and Nair, 2014). Overall, 9 out of 10 most polluted cities were located 
in the IGP, according to the 2018 World Health Organisation (WHO) list of most polluted cities in the world which is based on fine particulate matter $\left(\mathrm{PM}_{2.5}\right)$ from the year 2016 (Bhattacharya, 2016; WHO, 2018). At several ground-based measurement stations in the IGP maintained by the Central Pollution Control Board (CPCB; http://cpcb.nic.in/, last access: 17 July 2018), carbon monoxide (CO) levels amply exceeded the WHO guidelines $\left(100 \mathrm{mg} \mathrm{m}^{-3}\right.$ for $15 \mathrm{~min}$, $10 \mathrm{mg} \mathrm{m}^{-3}$ for $8 \mathrm{~h}$ ) and the more stringent Indian standards for $\mathrm{CO}\left(2 \mathrm{mg} \mathrm{m}^{-3}\right.$ for $8 \mathrm{~h}, 4 \mathrm{mg} \mathrm{m}^{-3}$ for $\left.1 \mathrm{~h}\right)$ during several days in November 2017 reaching 15 min average values up to $400 \mathrm{mg} \mathrm{m}^{-3}\left(1 \mathrm{mg} \mathrm{m}^{-3}\right.$ is roughly equal to $870 \mathrm{ppb}$ at ground level; we will use ppb from here on). The total population in the IGP region (including parts of Pakistan, Bangladesh and Nepal) exceeds 400 million and is growing. This means that the bad air quality is affecting hundreds of millions of people for a large part of the year. This makes it very important to investigate the origin and transport of pollution in the area. Due to its lifetime of several weeks, $\mathrm{CO}$ can also be used as a proxy of other, co-emitted, anthropogenic pollution.

Several explanations have been proposed for the high pollution levels in this period, but the exact cause is still unclear. Agriculture is very important in the IGP, with the postmonsoon burning of crop residues taking place in October and November. $\mathrm{CO}$ emissions from fires during this period are estimated, for example, by the Global Fire Assimilation System (GFAS) and the Global Fire Emissions Database (GFED). Other anthropogenic sources of CO, e.g., traffic and heating systems, are very high in the highly populated IGP, especially during the colder post-monsoon and winter months. Thus, apart from fire emissions from post-harvest burning practices, these other anthropogenic sources might be an important factor explaining the high $\mathrm{CO}$ pollution. In addition, post-monsoon meteorological conditions can lead to an accumulation of pollutants in northern India (Liu et al., 2018; Gani et al., 2018; Tiwari et al., 2014, 2015; Guttikunda and Gurjar, 2011).

Satellite data can play an important role in obtaining more insight in the origin and extent of pollution, providing information on the distribution of pollutants over large regions on a daily basis. In October 2017, the TROPOspheric Monitoring Instrument (TROPOMI) was launched, measuring various trace gases, including $\mathrm{CO}$, with unprecedented high spatial and temporal resolution (Landgraf et al., 2016). TROPOMI was still in its commissioning phase in November and algorithm tests and calibrations were ongoing. Fortunately, the first calibration results were positive and proved the high quality of the measurements and high signal-tonoise ratio (Borsdorff et al., 2018a; Borsdorff et al., 2018b), confirming the usefulness of the scientific data that were collected. TROPOMI observed very high column mixing ratios over the northern part of India from 11 to 19 November, in accordance with the ground-based data. The Copernicus Atmosphere Monitoring Service (CAMS; see Sect. 2.2) data showed similar enhancements in $\mathrm{CO}$ columns during this pe- riod, further corroborating the TROPOMI-retrieved CO variations (Borsdorff et al., 2018a).

In this study, we examine the high $\mathrm{CO}$ pollution episode of November 2017, focusing on 11-19 November, in more detail. We do this by comparing the daily $\mathrm{CO}$ observations over India from TROPOMI with ground-based measurements and simulated CO mixing ratios from the Weather Research and Forecast (WRF) model. We assess this according to our five objectives: whether TROPOMI is in accordance with ground-based measurements (1) and how well WRF is able to reproduce these data (2); how the pollution is dispersing over India (3), the role of meteorology in the accumulation and transport of $\mathrm{CO}$ (4), and shedding more light on sources contributing most to the high pollution over the IGP of India (5) in support of future pollution mitigation efforts.

The data and methods section describes the datasets that are used and the setup of the WRF model. In the results section, CO levels measured by TROPOMI over southeast Asia and by ground-level pollution measurement stations are compared with WRF data. The model is used also to attribute the high total column average mixing ratios over India to specific emission categories as presented in Sect. 4. In this section, the role of meteorological conditions is also discussed as well as the results of sensitivity tests on CO chemistry in the model.

\section{Data and methods}

\subsection{TROPOMI}

TROPOMI has a shortwave infrared spectrometer module, from which the total column average mixing ratio $(\mathrm{XCO})$ is retrieved using the measured radiance around $2.3 \mu \mathrm{m}$. Due to its high spatial and temporal resolution, TROPOMI is able to observe global CO vertical columns on a daily basis (Landgraf et al., 2016).

We used data from 14 orbits that TROPOMI retrieved 11-19 November 2017 that covered the northern part of India. The instrument reached near-nominal temperatures on 11 November, which is considered the first day of reliable data from TROPOMI (Borsdorff et al., 2018a). As in the study of Borsdorff et al. (2018a), in the first TROPOMI $\mathrm{CO}$ results, we used $\mathrm{XCO}$ values that were retrieved using the operational algorithm SICOR (shortwave infrared co retrieval; Landgraf et al., 2016). TROPOMI data were filtered for clear-sky observations, and cloudy-sky observations with a cloud top height $<5000 \mathrm{~m}$ and an aerosol optical thickness $>0.5$. Borsdorff et al. (2018c) found that including low-level cloud data increased the amount of available measurements, while hardly affected the ability to measure relatively small-scale sources by applying the SICOR algorithm to data from SCanning Imaging Absorption SpectroMeter for Atmospheric CHartographY (SCIAMACHY). This retrieval 
method allowed to include some measurements over the sea with low-level clouds (Borsdorff et al., 2018c).

We removed the two most westward pixels of every swath, which suffer from a not-yet-resolved performance issue (Borsdorff et al., 2018a). The first validation study showed that the TROPOMI data are in good agreement with CAMS data, with a global mean difference of $+3.2 \%$ and a Pearson correlation coefficient of 0.97 (Borsdorff et al., 2018b). For the India region, a $2.9 \%$ difference was found with CAMS with a standard deviation of $6 \%$ and a Pearson correlation coefficient of 0.9 (Borsdorff et al., 2018a). Moreover, only a small mean bias of $6 \mathrm{ppb}$, with a standard deviation of 3.9 and $2.4 \mathrm{ppb}$ for, respectively, clear and cloudy skies, has been found compared to ground-based total column measurements of TCCON (Total Carbon Column Observing Network). The signal-to-noise ratio of TROPOMI is high compared to previous satellite instruments retrieving CO (Borsdorff et al., 2018a).

The TROPOMI averaging kernel (AK) provides information on the vertical sensitivity of the satellite instrument for every single retrieved CO column (Borsdorff et al., 2014). The relationship between the reported $\mathrm{CO}$ vertical profile $\left(x_{\text {retr }}\right)$ and the true CO profile $\left(x_{\text {true }}\right)$ is given by Eq. (1). In this equation, $x_{\text {retr }}$ is the retrieved CO profile and $x_{\text {prior }}$ the a priori CO profile. According to Borsdorff et al. (2014):

$x_{\text {retr }}=x_{\text {prior }}+\boldsymbol{A} \boldsymbol{K}\left(x_{\text {true }}-x_{\text {prior }}\right)+e_{x}$,

where $e_{x}$ represents the error on the retrieved trace gas profile. The equation simplifies to Eq. (2),

$x_{\text {retr }}=\boldsymbol{A} \boldsymbol{K}\left(x_{\text {true }}\right)+e_{x}$,

when the effective null space contribution of the a priori profile is eliminated, which is the true for the chosen regularization parameter for the TROPOMI CO data, as is explained in Borsdorff et al. (2014). In this study, we compare the CO columns from TROPOMI, derived from $x_{\text {retr }}$, with the modeled columns from WRF. To make a fair comparison between the TROPOMI CO columns and the modeled CO columns, the AK has been applied in the same way to the modeled $\mathrm{CO}$ vertical profile (Eq. 2), by replacing $x_{\text {true }}$ with the modeled profiles and ignoring the error.

\subsection{CAMS}

CAMS (https://atmosphere.copernicus.eu, last access: $8 \mathrm{Au}-$ gust 2018) provides data on air quality in 6-hourly time intervals at a global horizontal resolution of $0.25^{\circ} \times 0.25^{\circ}$. The CAMS CO reanalysis product is derived from the output of a four-dimensional variational (4D-Var) data assimilation system, based on ECMWF (European Centre for Medium-Range Weather Forecasts) numerical weather prediction reanalysis data. It uses MACCity anthropogenic emissions, which combines information from the European Union MACC (Monitoring Atmospheric Composition and
Climate) and CityZen (megacity Zoom for the Environment emission database; Granier et al., 2011) inventories. For biomass burning, the GFAS fire emission inventory is used, which is based on MODIS fire counts and is provided at a $0.1^{\circ} \times 0.1^{\circ}$ resolution. The CAMS model is constrained by $\mathrm{CO}$ satellite observations from the Measurements of Pollution in the Troposphere (MOPITT) and the Infrared Atmospheric Sounding Interferometer (IASI) satellite instruments. Constraining the model with satellite observations provides a relatively good estimate of the actual XCO over the globe. Biases are found to be within $\pm 10 \%$ with respect to TCCON observations according to the latest validation report (KNMI, 2018), with data delivery lagging behind real time by about 1 week. In this research, we used the CAMS CO reanalysis products at 25 pressure levels and the total column product (http://apps.ecmwf.int/datasets/ data/cams-nrealtime/levtype=sfc/, last access: 11 September 2018). September-January total column CAMS data for the years 2012-2017 are used in Sect. 3.1.

\subsection{WRF}

To model XCO and ground concentrations at high spatial resolution, we used WRF version 3.8.1 (http://www.wrf-model. org/, last access: 2 January 2017) with the Advanced Research WRF core. WRF is a numerical non-hydrostatic model developed at the National Centers for Environmental Prediction (NCEP). It has several choices of physical parameterizations, allowing application of the model to a large range of spatial scales (Grell et al., 2005). Our model domain of $2900 \mathrm{~km}$ by $2010 \mathrm{~km}$ is over the northern part of India and parts of Pakistan, Nepal, China and Bangladesh, including parts of the Himalaya mountain range (see Fig. 1a). Our model employed a $10 \times 10 \mathrm{~km}^{2}$ resolution and 29 vertical eta levels, and used the Mellor-Yamada-Janjic planetary boundary scheme (Janjic, 1994), the unified Noah land surface model for surface physics (Ek et al., 2003; Tewari et al., 2004), and the Dudhia scheme (Dudhia, 1989) and the Rapid Radiative Transfer Method (Mlawer et al., 1997) for shortwave and longwave radiation, respectively. Cloud physics are solved with the Grell-Freitas cumulus physics ensemble scheme (Grell and Freitas, 2014).

Our boundary and input meteorological conditions, on a 6hourly basis, were based on ECMWF reanalysis data, similar to the CAMS model. WRF calculates its own meteorology in between these 6-hourly time steps and nudges towards the meteorological boundary conditions every $6 \mathrm{~h}$. The boundary conditions for $\mathrm{CO}$ came from the CAMS CO October and November data on pressure levels, interpolated to the WRF model levels.

Different CO emission inventories are available for southern Asia. As in CAMS, we used MACCity anthropogenic $\mathrm{CO}$ emissions for the year 2017 at a resolution of $0.5^{\circ} \times 0.5^{\circ}$ (Lamarque et al., 2010). We implemented nine different $\mathrm{CO}$ tracers representing the MACCity emission categories in 
Table 1. Overview of the different tracers implemented in WRF.

\begin{tabular}{lll}
\hline Tracer(short name) & Explanation & Source \\
\hline en_prod & Energy production and distribution & MACCity \\
res_com & Residential and commercial combustion & MACCity \\
agr_waste & Agricultural waste burning & MACCity \\
ind_proc & Industrial processes and combustion & MACCity \\
agr_prod & Agricultural production & MACCity \\
solv_proc & Solvent production & MACCity \\
land_transp & Land transport & MACCity \\
mar_transp & Maritime transport & MACCity \\
waste_treat & Waste treatment and disposal & MACCity \\
COgfas & Biomass burning & GFAS \\
CObg & Boundary condition, referred to as "background" & CAMS \\
\hline
\end{tabular}

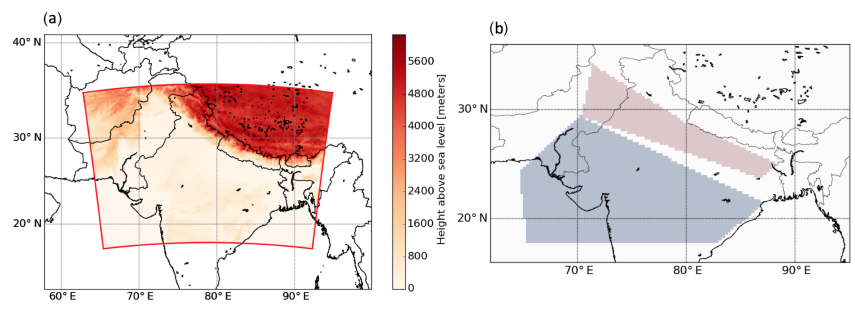

Figure 1. (a) WRF domain over India; the colors depict the height above sea level (m), showing the Himalaya mountain range. (b) Within the WRF domain: the area for averaging over the IGP (pink) and for averaging over non-IGP India (blue).

WRF-Chem (see Table 1). The MACCity database estimates worldwide monthly emission strengths for these emission categories. An additional tracer was used to account for $\mathrm{CO}$ transported from the CAMS-derived boundary conditions: we refer to this $\mathrm{CO}$ tracer as "background" in this paper (Table 1).

For biomass burning emissions, we used GFAS data with a resolution of $0.1^{\circ} \times 0.1^{\circ}$ (available for download from http: //apps.ecmwf.int/datasets/data/cams-gfas/, last access: $3 \mathrm{Au}-$ gust 2018). However, there are strong signs that fire emission inventory datasets, such as GFAS and GFED, do not capture all of the biomass burning emissions (Mota and Wooster, 2018; Cusworth et al., 2018; Huijnen et al., 2016). Also, the conversion of fire occurrence to $\mathrm{CO}$ emissions depends on factors such as combustion efficiency, biome type and soil characteristics, which adds uncertainty to the emission estimates (Werf van der et al., 2010). For PM, it is estimated that the GFAS emissions are underestimated by approximately a factor of 2-6 (Mota and Wooster, 2018; Cusworth et al., 2018; Huijnen et al., 2016). For CO, less information is available but since its emissions are linked to those of other compounds, similar underestimates are expected.

In our base setup, we ran the model for the period 1 October-20 November; including the tracers listed in Table 1, so including the original GFAS emissions and the background. In this paper, results are shown for 1120 November, October is considered as a spinup period. Besides the base run, we did some extra simulations including 0 (referred to as MACCity), 1 (base setup), 5 (+5GFAS) and $10(+10$ GFAS $)$ times the original GFAS emissions, based on the estimated underestimation of fire PM emissions.

Deposition and chemical production from volatile organic compounds (VOCs) are not included in our base setup. The deposition process is slow compared to transport of $\mathrm{CO}$ out of the model domain, and direct $\mathrm{CO}$ sources over the highly populated (IGP) region of northern India are much larger than the indirect source from VOC oxidation.

However, in a sensitivity simulation (see Sect. 4.3), we accounted for the chemical reaction between the hydroxyl radical $(\mathrm{OH})$ and $\mathrm{CO}$ using the JPL-recommended temperatureand pressure-dependent reaction rate (Burkholder et al., 2015). Carbon monoxide production from the oxidation of methane and other VOCs is included in this simulation as well. In this chemistry simulation, we used the $\mathrm{CO}$ production from the TM5-4DVar system (Krol et al., 2013) and the corresponding $\mathrm{OH}$ climatology, based on Spivakovsky et al. (2000), scaled by 0.92 (Huijnen et al., 2010; Huijnen et al., 2016; Krol et al., 2013).

\subsection{Ground-level measurements}

The Central Pollution Control Board (CPCB) of India measures the air quality at several stations in India (http:// cpcb.nic.in/automatic-monitoring-data/, last access: 1 October 2018). All the samples are taken at ground level and are made available as $15 \mathrm{~min}$ averages. We only used stations here with $\mathrm{CO}$ measurements available for 15 October20 November. To obtain measurements representative of the urban background, we excluded stations near large roads showing large $\mathrm{CO}$ enhancements. This selection is needed for a meaningful comparison to WRF simulations at $10 \times 10 \mathrm{~km}^{2}$ using MACCity emissions at only $0.5^{\circ} \times 0.5^{\circ}$ resolution. In Fig. 2, all stations used for comparison with WRF are listed. 


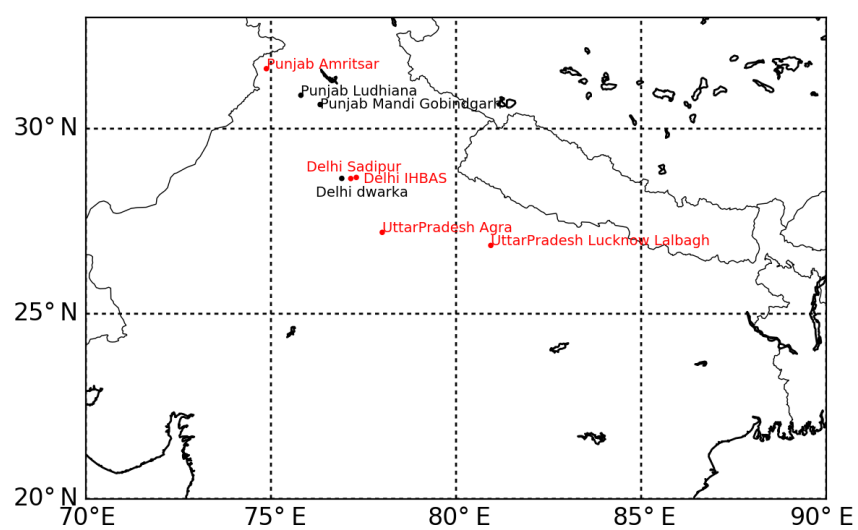

Figure 2. Locations of ground-level measurement stations: red dots and labels are inner-city stations; black dots and labels are outer-city locations.

\subsection{Comparing WRF with TROPOMI and ground-level measurements}

As outlined in Sect. 2.1, the averaging kernel was applied to the WRF data using Eq. (2). Both WRF and TROPOMI data were averaged on a $0.25^{\circ} \times 0.25^{\circ}$ grid to make the comparison less sensitive to local outliers in the data. We averaged over several days of data, concentrating on two periods (1114 and 15-19 November 2017), in order to obtain a gap-free image of northern India (on 18 November, no TROPOMI data were available). We selected these two periods spanning an equal number of days based on the patterns seen in TROPOMI data and the weather conditions (see Sect. 4.2). In the first period, TROPOMI data show high $\mathrm{CO}$ pollution over the whole IGP. The second period shows lower XCO, due to changing weather conditions (see Sect. 4.2). In some comparisons, results are averaged over two regions of India: the IGP and the area south of the IGP (non-IGP), as defined in Fig. 1b.

We divided the ground-level measurement stations in India into two groups: one group consisted of stations directly in the city and the other group of stations was at the city edge in surrounding rural background regions (Fig. 2, red and black labels indicate the inner and outer city, respectively). This distinction was used to investigate differences in the source signature of $\mathrm{CO}$ inside and outside of cities.

\section{Results}

\subsection{TROPOMI and CAMS over southeast Asia}

In some of the first TROPOMI observations collected in the first half of November 2017, the northern part of India, more specifically, the IGP, stood out by its high XCO values (see Fig. 3). XCO values were even significantly higher over the IGP than over any region of southeast Asia, even higher than over China. This is remarkable, since in earlier studies, China

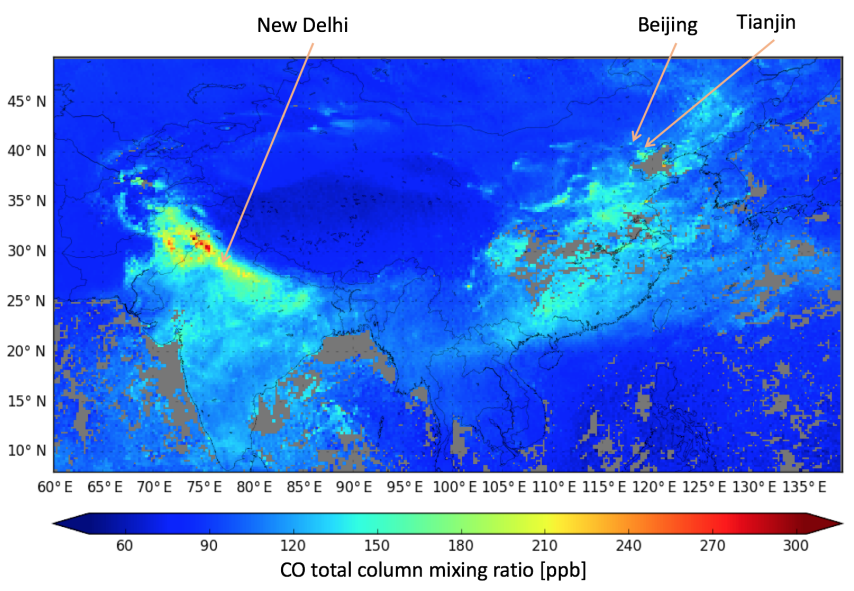

Figure 3. XCO over India and China as observed by TROPOMI (13 November 2017) comparing New Delhi with large CO-emitting cities in China (Beijing and Tianjin).

was the most polluted region of the world (e.g., Baldasano et al., 2003; Kan et al., 2012). On the other hand, China has recently been active in reducing air-polluting emissions, including CO (Zheng et al., 2018), while in India, emissions continued to increase over the past years (Krotkov et al., 2016).

It was estimated that China reduced its $\mathrm{CO}$ emissions by $23 \%$ between 2013 and 2017 (Zheng et al., 2018). India only took its first steps to improve the air quality in December 2017 by implementing the National Clean Air Program (NCAP), i.e., after the high-pollution event studied in this paper. This makes it plausible that the New Delhi region was more polluted in this period than any region over China. NCAP does not yet include strict targets for emission reductions and rather focuses on setting up an effective ambient air quality monitoring network and making plans for prevention, control and abatement of air pollution (Ganguly, 2018).

To determine how unique these high $\mathrm{CO}$ values were during this time of the year over the IGP, we analyzed the last 4 years of CAMS data. The results confirm that the highpollution episode of November 2017 was exceptionally long, with more than 2 weeks of $\mathrm{CO}$ column amounts exceeding $0.0015 \mathrm{mg} \mathrm{m}^{-2}$. However, according to the CAMS model, $\mathrm{CO}$ columns reached short-term values that were higher during December 2014 and 2015 than in November 2017 (Fig. 4). The high CO columns of November 2017 are therefore not unique for this part of India. These high-pollution episodes during the post-monsoon period occur more frequently in recent years (Fig. 4). As long as emissions are not reduced, India will probably encounter such events more often in future post-monsoon and winter seasons. 


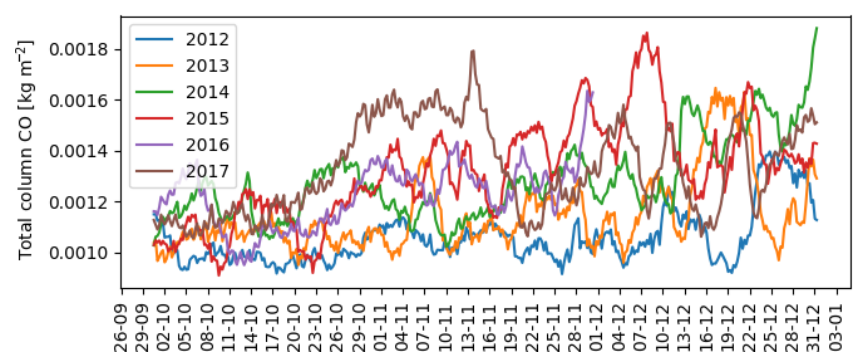

Figure 4. CAMS CO columns $\left(\mathrm{kg} \mathrm{m}^{-2}\right)$ from October to December (2012-2017) averaged over the IGP domain (see Fig. 1).

\subsection{Comparing WRF to TROPOMI}

\subsubsection{Agreement between WRF and TROPOMI}

We compared our WRF results with the TROPOMI data and found that WRF could reasonably well reproduce the high XCO values spread over the whole IGP during 1114 November 2017 and the lower XCO values during 15-19 November. Figure 5 shows that both modeled and TROPOMI-retrieved XCO are very high in the northwest of India (Fig. 5a, c and e). The highest spatial correlation between WRF (including standard GFAS emissions) and TROPOMI is found on 11, 12 and 13 November $(r=$ $0.87,0.88$ and 0.88 , respectively). On 14 and 15 November, poorer correlations of 0.78 and 0.76 are found, respectively. The model captures the transition between the two periods slightly differently from the observations, with TROPOMI showing ventilation of $\mathrm{CO}$ to the southeast earlier than WRF. The spatial correlation went up again to 0.81 for 16 and 17 November and 0.85 for 19 November. The WRF simulation underestimates XCO during the 11-14 November period over the IGP (Fig. 5a). Adding either $20 \%$ extra MACCity emissions or adding substantial amounts of GFAS fire emissions, between $500 \%$ (Fig. 5e) and $1000 \%$ of regular GFAS emissions gave XCO values that are more similar to the TROPOMI values without notable changes in the spatial patterns over India. In all cases, WRF overestimated the $\mathrm{CO}$ levels at the border of Pakistan south of the IGP. For 15-19 November, however, the simulations with MACCity and standard GFAS emissions already overestimate the XCO measured by TROPOMI (Fig. 5b). This might have to do with a deviation in the changing meteorological conditions in WRF. The simulations in WRF did not include the atmospheric chemistry, but this is probably only playing a minor role (see Sect. 4.3).

\subsubsection{CO columns over and outside of the Indo-Gangetic Plain}

The XCO levels measured by TROPOMI and modeled by WRF are clearly enhanced during 11-14 November over the IGP compared to more southerly regions of India (non-
IGP, Fig. 6). The IGP CO total columns are on average $30 \mathrm{ppb}$ higher than over non-IGP regions (see Fig. 1b for areas of IGP and non-IGP). When we average over 1519 November, this difference between the IGP and the nonIGP mostly disappears; the column average XCO over the IGP is now lowered from 162 to $129 \mathrm{ppb}$ for TROPOMI and from 152 to $124 \mathrm{ppb}$ for WRF, while the non-IGP XCO only slightly decreased for TROPOMI (124 to $118 \mathrm{ppb}$ ) and remained nearly equal at $129 \mathrm{ppb}$ for WRF. A WRF simulation based on MACCity without GFAS (green bars), shows the same XCO pattern. Since the emissions of MACCity are not changing day by day, the difference between the periods is solely caused by different meteorological conditions (see also Sect. 4.2).

\subsection{Comparing WRF to ground-level measurements}

$\mathrm{CO}$ concentrations at the ground-level measurement stations that are used generally increased until 14 November, compared to earlier measurements. This is in accordance with the total column CO levels seen in the 2017 time series from CAMS. The CO diurnal cycles of the observations and the simulation show clear nighttime accumulation in the stable nocturnal boundary layer, which vanishes during daytime with increasing boundary layer depth. The CO concentrations generally reach lower levels after 16 November (Fig. 7). The WRF model largely follows the CO enhancement and reduction pattern, although the diurnal cycle seems delayed by $3 \mathrm{~h}$ compared to the ground-based measurements. This might be due to the hourly time profiles that were used for the emissions, which were derived for Europe (van der Gon et al., 2011), but do account for the local time shift. In Fig. 7, we zoom in on 11-20 November, the days for which also TROPOMI data are available. Averaged time series are shown of the measurements collected at stations in the provinces of Delhi, Punjab and Uttar Pradesh and the corresponding averaged WRF concentrations. The stations inside the cities (Fig. 7a) show a clear reduction in mixing ratio during the latter half of this period $(1050 \mathrm{ppb}, 15$ 19 November), compared to the first half (1700 ppb, 1114 November). The observed reduction, which we observed also in TROPOMI XCO, is reproduced by WRF (1400 to $880 \mathrm{ppb}$ ). At locations outside cities (Fig. 7b), this pattern is less pronounced, both in WRF and in the measurements. WRF largely follows the measured $\mathrm{CO}$ mixing ratios, but slightly underestimates the $\mathrm{CO}$ values after the 16 November. WRF shows enhanced XCO during 15 and 16 November, which is not observed.

To further investigate the origin of the $\mathrm{XCO}$ variations, the contribution of different emission categories in WRF is shown in Fig. 8. We show here the inner-city stations, as these are the areas where most people live, but the picture is not very different for outer-city stations (see also Table 2, Sect. 4.1). As can be seen, the surface concentrations are much less sensitive to the background $\mathrm{CO}$ (black) compared 
(a) WRF base setup 11-14 Nov
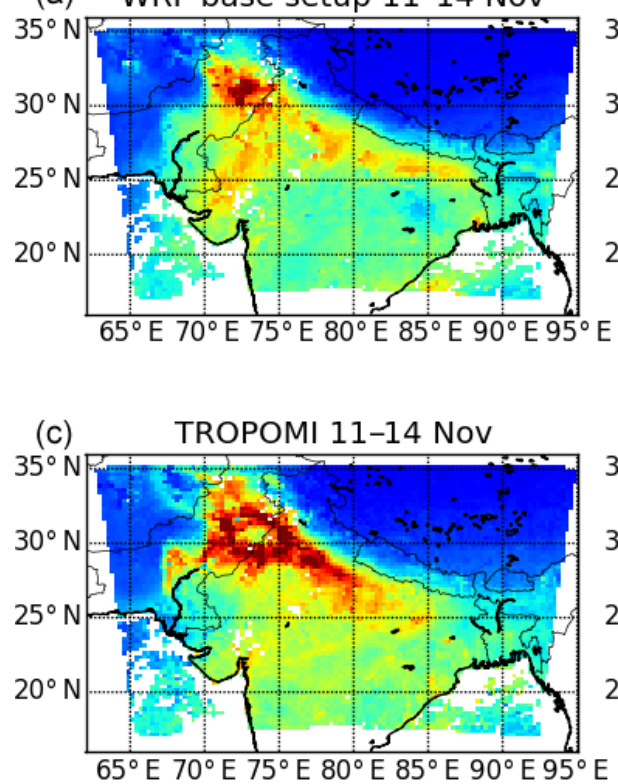

(b) WRF base setup 15-19 Nov

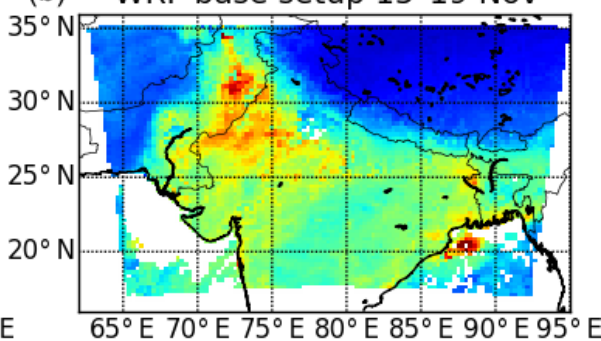

(d) TROPOMI 15-19 Nov

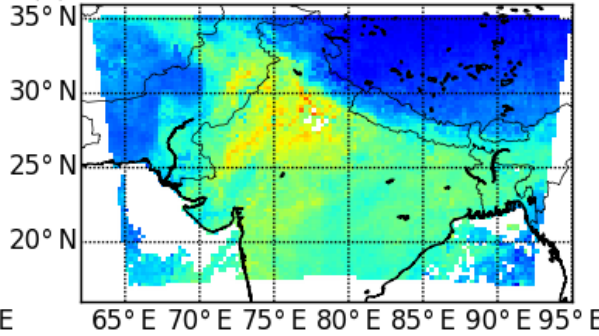

(e) WRF +5GFAS 11-14 Nov

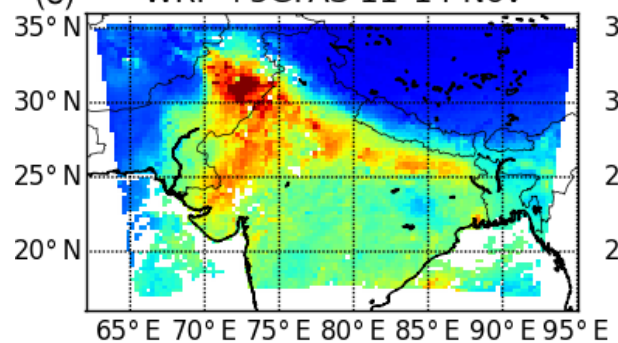

(f) WRF + 5GFAS 15-19 Nov

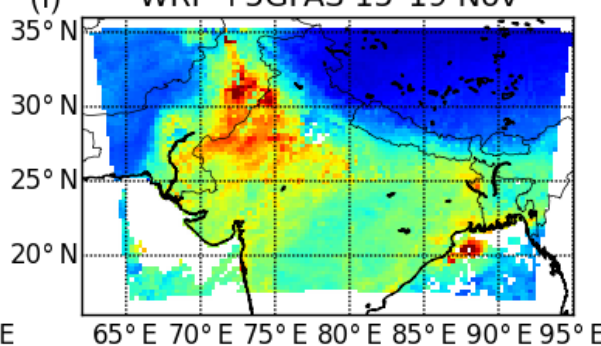

60

80

$100 \quad 120$

20140

160

180

200

Figure 5. (a) WRF simulated total columns with MACCity emissions, with $1 \times$ GFAS emissions, 11-14 November; panel (b) is the same as (a), but for 15-19 November; (c) TROPOMI total columns, 11-14 November; panel (d) is the same as (c) but for 15-19 November; (e) WRF simulated total columns with MACCity emissions including 5× GFAS fire emissions, 11-14 November; panel (f) is the same as (e) but for 15-19 November.

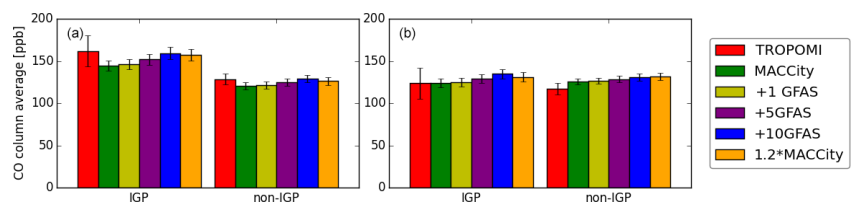

Figure 6. CO averaged over the IGP and non-IGP areas (a) for the period 11-14 November and (b) for 15-19 November. The $1 \sigma$ error bars denote the spread over the different days in the averaging period.

to the total column mixing ratios. On all days, the category "residential and commercial combustion" contributes most to the total CO concentration (on average $67 \%$ for ground level and $35 \%$ for the total column including the background).
Other large contributors are "industrial processes and combustion" and "traffic". Surprisingly, we find a rather small contribution from fires to the total mixing ratio of $1 \%-2 \%$ in our simulation with MACCity and standard GFAS emissions (see Sect. 4.1, Table 2). Even with strongly enhanced GFAS emissions, the contribution remains on average within $20 \%$. The larger XCO measured at inner-city stations - compared to the stations outside the cities - also points to large contributions from urban emissions.

\section{Discussion}

We found XCO values of over $200 \mathrm{ppb}$ in substantial parts of northern India in both the TROPOMI and model simulations. From the satellite data and total column WRF mixing ratios, 

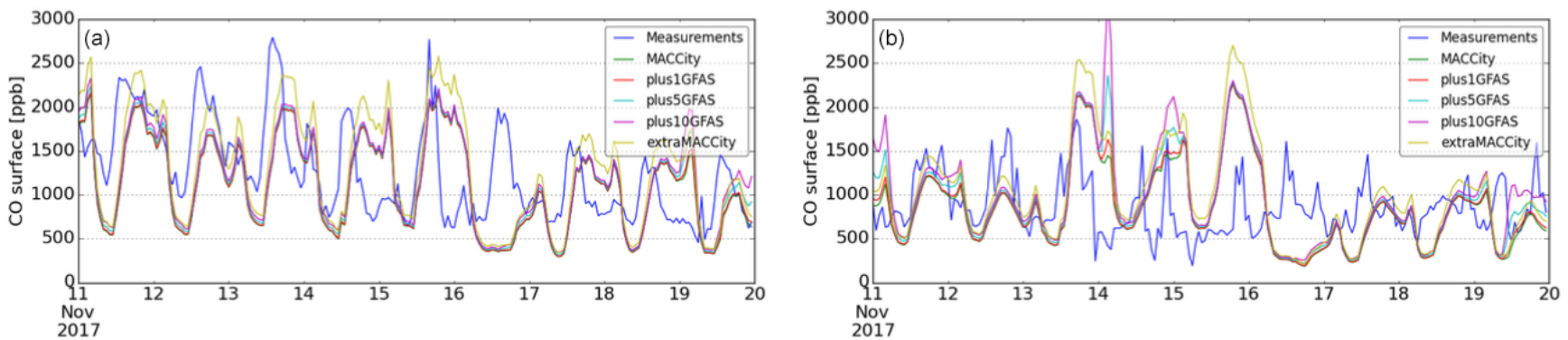

Figure 7. (a) Ground-level measurements and WRF-model-averaged CO over inner-city stations (ppb; see Fig. 2); time is in UTC. (b) Ground-level measurements and WRF model averaged over stations outside cities (ppb; see Fig. 2)
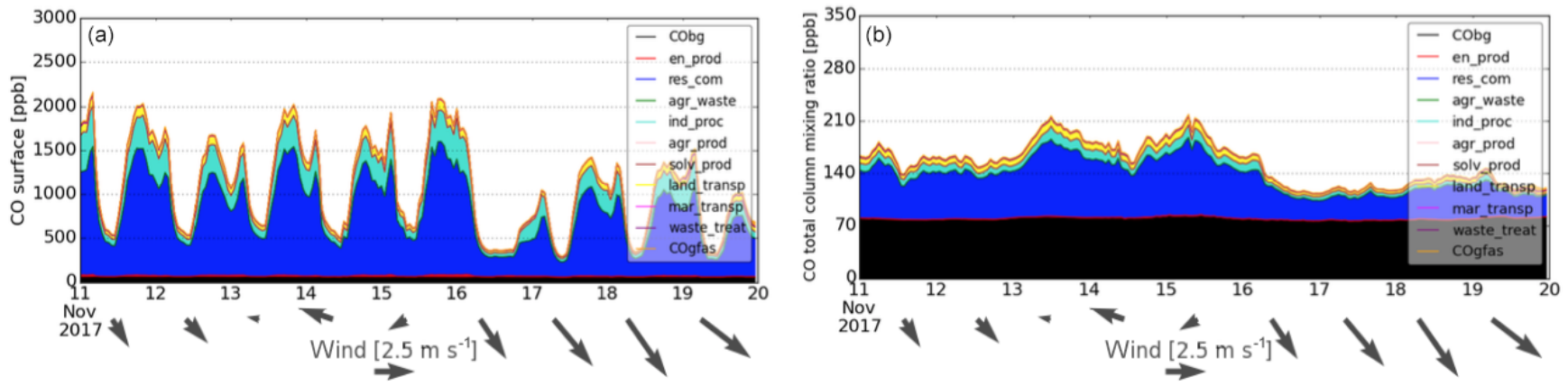

Figure 8. Average inner-city source contribution to (a) ground level and (b) total column mixing ratio; time is in UTC. Below the mixing ratios, the $10 \mathrm{~m}$ wind speed and direction are depicted; longer arrows indicate higher wind speeds (see legend).

it is clear that CO is not only enhanced directly around Delhi but over the whole IGP, with very high values west of Delhi. This means that not only the people living in Delhi but also a large part of the hundreds of millions of people inhabiting the rest of the IGP are affected by the bad air quality.

\subsection{Contribution of different sources}

According to the tracer simulations in our model that are based on MACCity and GFAS emissions, more than $50 \%$ of the CO near ground level in November 2017 was caused by residential and commercial combustion. Other main contributors are industrial combustion and traffic. For the total column mixing ratios, the background $\mathrm{CO}$, entering from the boundaries of the domain, was clearly more important and responsible for around $30 \%-50 \%$ of the total column mixing ratio (see Fig. 4). The background $\mathrm{CO}$ is, however, rather constant, and day-to-day variations in XCO are caused by residential and commercial combustion, similar to what we observed at ground level. The $\mathrm{CO}$ emission contribution from fires has certainly a more episodic nature than the anthropogenic sources in MACCity. In this section, we do not only include the average contribution, but also consider the maximum contribution of fire emissions to investigate short-term variations in the contribution of fires to $\mathrm{CO}$.

At the measurement stations that we considered, except for Punjab at ground level, only a minor contribution from fire of
$1 \%$ to $2 \%$ was found, both for total column and ground-level CO (see Table 2). The steady increase in CO levels started before 11 November; to make sure we did not miss part of the biomass burning contribution, we included in Table 2 also a longer period of the post-monsoon season: 1 October19 November. At ground level in Punjab, the average and maximum contributions were, respectively, $6 \%$ and $44 \%$, over the whole modeled period of 1 October-19 November. In the 11-19 November period, the maximum contribution of biomass burning to the ground-level contribution there was $23 \%$, with an average of $2 \%$ (see Table 2).

Some ground stations were excluded because of the proximity to large $\mathrm{CO}$ sources, leading to very high observed $\mathrm{CO}$ concentrations. Although these measured enhancements are likely traffic related, it is possible that some of the enhancements are caused by local biomass burning. Overall, however, our results point to a relatively small role of biomass burning in the enhanced $\mathrm{CO}$ concentrations over the largest part of the IGP, as shown in Fig. 8 for inner-city stations. A similar contribution of biomass burning is found outside of the city (not shown).

There are strong indications, however, that GFAS might severely underestimate the fire emissions (Mota and Wooster, 2018). Cusworth et al. (2018) concluded in their recent paper on biomass burning in India that the resolution of the MODIS satellite instrument, on which GFAS fire emissions are partly based, misses many small fires. In addition, thick 
smoke from fires might lead to an underestimation of fire emissions from GFAS, as MODIS might identify these as clouds, as was found in a recent study over Indonesia (Huijnen et al., 2016). The results of increasing the fire emissions by a factor of 5-10 in WRF are shown in Figs. 5 and 6. Adding biomass burning emissions in the WRF simulation does not lead to a higher spatial correlation between WRF and TROPOMI, but CO levels get closer to TROPOMI values in the 11-14 November period, so it might be that the GFAS fire emissions were indeed underestimated in this period, or a substantial amount of fires is missed in GFAS in this period. However, the mixing ratios during the 15-19 November period are overestimated with respect to TROPOMI when higher GFAS emissions are assumed (see Figs. 5, 6). Alternatively, MACCity already explains a very large part of the observed CO levels, and increasing the MACCity emissions by $20 \%$ gives rather comparable results to increasing the GFAS fire emissions by a factor of 5-10 for the total columns (Fig. 6). Biomass burning would still be a minor contributor to the average $\mathrm{CO}$ levels even if the emissions are enhanced by these factors.

For Delhi and Uttar Pradesh, the contributions of fire emissions to the total CO levels are on average minor, even if the GFAS emissions are increased. For Punjab, we find that fire emissions might have contributed significantly to the ground-level concentrations for a few days in the 1 October19 November period. From the total column and other stations, however, we conclude that MACCity already explains a very large part of the observed $\mathrm{XCO}$ and ground-based $\mathrm{CO}$ levels, and fire emissions can only have played a very minor role.

In this paper, however, we assume that the emissions of MACCity do not grossly overestimate $\mathrm{CO}$ emissions over the IGP. Compared to TROPOMI and the amount of emissions that might come from fires based on GFAS and GFED, this assumption seems legitimate. When comparing the total emissions of MACCity to the Emissions Database for Global Atmospheric Research (EDGAR v4.3.1) of the most recent year (2010); however, EDGAR v4.3.1 gives for November an approximately $20 \%$ lower emission estimate, when taking emission factors of van der Gon et al. (2011) to convert from yearly emission to monthly emission. This gives more space to add extra emissions of GFAS, although we should keep in mind that in that case we have to increase the emissions of GFAS even more radically, in the order of $>30$ times the original emissions.

\subsection{Meteorological conditions}

In general, the post-monsoon and winter season are the seasons with the worst air quality in the IGP. The photochemical loss is low and other meteorological variables, e.g., the absence of rain and low wind speeds, contribute to high levels of pollution. Several studies have been performed studying this relation for Delhi based on PM (e.g., Gani et al.,
2018; Tiwari et al., 2015; Guttikunda and Gurjar, 2011). Guttikunda and Gurjar (2011), for example, found that even with constant emissions over each month, the estimated tracer concentrations were $40 \%-80 \%$ higher in November, December and January, and $10 \%$ to $60 \%$ lower in May, June and July, compared to the annual average.

For November 2017, we identified meteorological conditions as the most important reason for why the $\mathrm{CO}$ mixing ratios at ground level and in the total column increased as observed. Although not extreme, the meteorological conditions were favorable for the accumulation of air pollutants. The wind speeds near the surface were low for several weeks: $<2.5 \mathrm{~m} \mathrm{~s}^{-1}$ at $10 \mathrm{~m}$ height, limiting the advection of $\mathrm{CO}$ away from the sources (Fig. 9). The temperatures were relatively low, decreasing from 22 to $16^{\circ} \mathrm{C}$ from 1 to 19 November, thus limiting vertical convection. The planetary boundary layer heights were low with daily averages between 350 and $580 \mathrm{~m}$, diagnosed from WRF, while the air pressure (around $990 \mathrm{hPa}$ ) and relative humidity (up to $70 \%$ ) were relatively high (Fig. 9). The most important changes that we found in meteorological parameters around 15 November, when the $\mathrm{CO}$ concentrations started decreasing, are in the wind speed, the wind direction, the relative humidity and the boundary layer height. As can be seen in Fig. 8, the wind speeds clearly increased after 15 November and the wind direction changed from a northwesterly direction to easterly winds in this period of the highest $\mathrm{CO}$ concentrations and the start of the ventilation. The relative humidity (RH) went up from $55 \%$ to $70 \%$ on 15 November and decreased afterwards to $45 \%$. The boundary layer was highest on 18 November $(580 \mathrm{~m}$; see Fig. 9) but we found that more to the northwest of the IGP, closer to the Himalayas, boundary layer heights were also exceeding the height of this mountain ridge on 14 and 15 November (not shown). The highest CO values around Delhi were found during 13-16 November, so just before the winds were turning and increasing. In our WRF simulation, the most important contributors to the decrease in $\mathrm{CO}$ were both the ventilation of the IGP with clean air from the Himalayas, followed by advection of the pollution to the southeast, which took place over all days after 15 November, and the outflow of $\mathrm{CO}$ towards the northwest, around the Himalayas, in the upper troposphere. We could clearly observe this outflow of CO in the upper layers of WRF on 14 and 15 November and it was also visible in the TROPOMI measurements on the same days (see also Borsdorff et al., 2018a). The emissions of MACCity that went into the WRF simulation with only MACCity emissions were the same every day of November, which means that the increase and decrease in $\mathrm{CO}$ levels in the MACCity-only run (Figs. 6, 7) were due to the meteorological conditions.

Meteorological variability in relation with $\mathrm{CO}$ pollution was studied before by Verma et al. (2017), who focused on Agra, Uttar Pradesh, $100 \mathrm{~km}$ southeast of New Delhi. The meteorological conditions they reported for November 2015 
Table 2. Contribution of standard GFAS biomass burning to the total CO levels per region at ground level (GL) and in the total column (TC) between 11 and 19 November 2017.

\begin{tabular}{llllllllll}
\hline Period & & $\begin{array}{l}\text { Delhi } \\
\text { GL }\end{array}$ & $\begin{array}{l}\text { Delhi } \\
\text { TC }\end{array}$ & $\begin{array}{l}\text { Punjab } \\
\text { GL }\end{array}$ & $\begin{array}{l}\text { Punjab } \\
\text { TC }\end{array}$ & $\begin{array}{l}\text { Uttar } \\
\text { Pradesh } \\
\text { GL }\end{array}$ & $\begin{array}{l}\text { Uttar } \\
\text { Pradesh } \\
\text { TC }\end{array}$ & $\begin{array}{l}\text { Inner- } \\
\text { city } \\
\text { GL }\end{array}$ & $\begin{array}{l}\text { Outer- } \\
\text { city } \\
\text { GL }\end{array}$ \\
\hline $\begin{array}{lllllll}11-19 \\
\text { November }\end{array}$ & Maximum & $12 \%$ & $11 \%$ & $23 \%$ & $10 \%$ & $3 \%$ & $3 \%$ & $14 \%$ & $23 \%$ \\
\hline $\begin{array}{l}1 \text { October- } \\
19 \text { November }\end{array}$ & Maximum & $17 \%$ & $1 \%$ & $2 \%$ & $1 \%$ & $1 \%$ & $1 \%$ & $1 \%$ & $2 \%$ \\
\hline
\end{tabular}

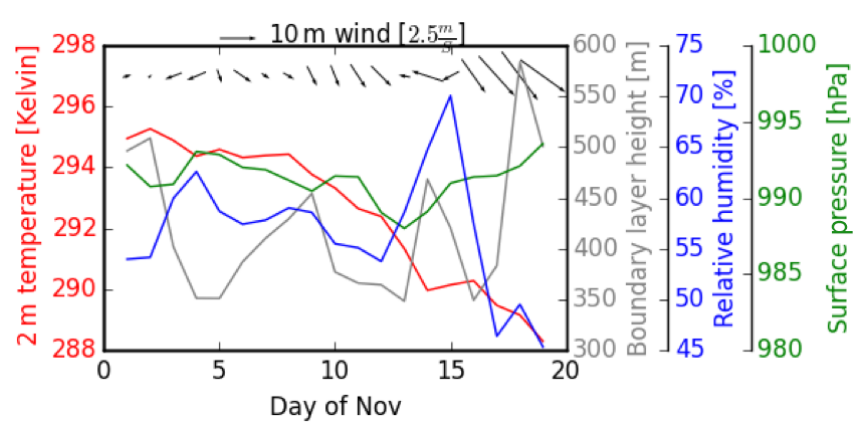

Figure 9. WRF $24 \mathrm{~h}$ average meteorology over an area of $70 \times$ $40 \mathrm{~km}^{2}$ around Delhi and Agra in November 2017: $2 \mathrm{~m}$ temperature (red, left axis), boundary layer height (gray, right axis), relative humidity (blue, right axis), surface pressure (green, right axis) and $10 \mathrm{~m}$ wind speed and direction (black arrows; key gives length of $2.5 \mathrm{~m} \mathrm{~s}^{-1}$ wind). The transition from high to low CO levels takes place around 15 November.

were similar to what we found for November 2017. However, the $\mathrm{RH}$ peak of $70 \%$ we found was in the upper $25 \%$ of their measurements for November, and the boundary layer was shallower than the lowest level of $450 \mathrm{~m}$ they found in their study. We should remark here that the meteorology in our study is based on WRF model simulations, while in Verma et al. (2017), the meteorology came from automatic weather stations, except for the boundary layer height, which was obtained from the MERRA (Modern-Era Retrospective analysis for Research and Applications) reanalysis. From the meteorological and observational data, we conclude that there is a similar build of pollution in 2017 as in the 2015 study; however, circumstances for $\mathrm{CO}$ accumulations were slightly stronger in November 2017. In our study, as in Verma et al. (2017), stagnant weather conditions are an important cause of the high pollution levels.

\subsection{The effect of chemistry and VOC emissions}

In the base setup of WRF, we did not include indirect $\mathrm{CO}$ sources from, e.g., VOC oxidation in the analysis. Also, we did not include the $\mathrm{OH}$ oxidation of $\mathrm{CO}$, and the only sink of $\mathrm{CO}$ was outflow at the lateral boundaries of the model. To assess the importance of VOC oxidation to the XCO and ground-level concentration, we performed a few sensitivity simulations, including indirect $\mathrm{CO}$ sources from VOCs and methane and the oxidation of $\mathrm{CO}$ by $\mathrm{OH}$. The most important differences were found over the region directly around New Delhi. XCO increased by up to $4 \%$ due to the oxidation of VOCs and methane. Oxidation of $\mathrm{CO}$ by $\mathrm{OH}$ led to a decrease of up to $7 \%$ and, combining both mechanisms, a net decrease in XCO of up to $4 \%$ was found in the New Delhi region. In the non-IGP area, the effects of VOC oxidation, $\mathrm{OH}$ removal and the two combined were, respectively, $+2 \%,-5 \%$ and $-2 \%$ on the XCO. Over the IGP, effects are somewhere in between. Patterns of XCO enhancement over India were hardly affected by VOCs and $\mathrm{OH}$ oxidation. Compared to the uncertainty in the emissions, we consider these model simplifications unimportant and therefore justified for the goals of this study.

\section{Summary and conclusions}

TROPOMI showed very high levels of XCO (>280 ppb) over northern India during the high-pollution event in India in November 2017. TROPOMI captured the spatial pattern of the pollution, covering not only Delhi but rather the whole IGP. This demonstrates the high importance of investigating the sources and the transport of pollution, as hundreds of millions of people are living in the IGP and their health is likely affected by the bad air quality. CO is very suitable for investigating air pollution, not only because of the negative health impact of $\mathrm{CO}$ itself but also as tracer to track the dispersion of other pollutants, due to its lifetime of several weeks. November is in the post-monsoon crop-burning season, and media and scientific papers pointed to emissions from crop residue burning as the main reason for the high pollution levels over the IGP (Jha, 2017; Vadrevu et al., 2011; Liu et al., 2018; Cusworth et al., 2018).

In this study, we analyzed two consecutive periods in November: 11-14 November, with the highest CO levels, and 15-19 November, when CO levels decreased. High $\mathrm{CO}$ levels and a subsequent drop in $\mathrm{CO}$ were observed by TROPOMI in ground-level measurements and in our WRF simulations. The meteorological situation, characterized by low wind speeds and shallow atmospheric boundary layers, 
was most likely the primary explanation for the temporal accumulation of regionally emitted $\mathrm{CO}$ in the atmosphere. The increase in wind speed and change of wind direction around 14 November led to the subsequent dispersion. The dominant role of meteorology, rather than emission variations, is supported by the fact that the WRF simulations that used constant emissions during the whole period showed a similar temporal dependence, including decreasing $\mathrm{CO}$ levels after 15 November.

After analyzing the contribution of specific emission sectors to the simulated and observed CO levels over India, we conclude that residential and commercial combustion explain the largest fraction of the high CO pollution over the IGP. Biomass burning only plays a minor role in the $\mathrm{CO}$ enhancement: on average $1 \%-2 \%$ at ground level and only $1 \%$ to the total column pollution level. In earlier studies, it was found that the GFAS biomass burning data, used in our analyses, likely underestimate the actual emissions of $\mathrm{CO}$ (Mota and Wooster, 2018; Cusworth et al., 2018; Huijnen et al., 2016). The comparison of TROPOMI data with our WRF simulations, based on MACCity and GFAS data, confirms that $\mathrm{CO}$ emissions are underestimated in the 11-14 November period. The difference could be accounted for by increasing the GFAS emissions by $500 \%-1000 \%$, a rather large increase compared to the $200 \%-600 \%$ increase found in the last named studies. Fires missed by GFAS observations might explain part of this increase. In that case, the contribution of biomass burning to the observed pollution levels becomes more important: on the order of $5 \%-20 \%$, but it would still remain smaller than the contribution of urban $\mathrm{CO}$ emissions. Therefore, unless urban MACCity emissions are largely overestimated and GFAS emissions are underestimated even more, which we consider a less likely scenario, the contribution of urban $\mathrm{CO}$ emissions is the most important contributor to the $\mathrm{CO}$ pollution inside and outside of the cities. These findings have important implications for emission mitigation efforts to avoid extreme pollution levels over the IGP during the post-monsoon period.

Our results have implications for ongoing wintertime pollution mitigation efforts in India. Meteorology is found to be a key driver of the extreme pollution episodes, however, in conjunction with strong $\mathrm{CO}$ emissions. Hence, to mitigate the pollution, reducing the largest $\mathrm{CO}$ emission sources (residential and commercial combustion) remains the best solution, short term and long term.

Data availability. Data used in this study can be found under ftp: //ftp.sron.nl/open-access-data-2/TROPOMI/tropomi/ (last access: 5 February 2019).

Author contributions. IND, SH, MK, TR, SP and IA were active in the conceptualization of the study and designed the methodology. ID performed the model simulations, carried out data analysis and wrote the manuscript. SH mentored ID. SP, TB and JL helped with the resources: SP with the acquisition of the Indian surface measurements, and TB and JL provided the TROPOMI data. All authors contributed to revising the manuscript.

Competing interests. The authors declare that they have no conflict of interest.

Special issue statement. This article is part of the special issue "TROPOMI on Sentinel-5 Precursor: first year in operation (AMT/ACPT inter-journal SI)". It is not associated with a conference.

Acknowledgements. We would like to thank Antje Inness (ECMWF) for helping us with the analysis by providing CAMS data and an explanation of the data. The GFAS data were generated using Copernicus Atmosphere Monitoring Service Information 2017.

Edited by: Robert Harley

Reviewed by: two anonymous referees

\section{References}

Baldasano, J., Valera, E., and Jimenez, P.: Air quality data from large cities, Sci. Total Environ., 307, 141-165, 2003.

Bhattacharya, A.: Why our northern plains are world's most polluted area, The Economic Times, available at: https: //economictimes.indiatimes.com/news/environment/pollution/ why-our-northern-plains-are-worlds-most-polluted-area/ articleshow/52248783.cms (last accessed: 5 November 2018), 2016.

Borsdorff, T., Hasekamp, O. P., Wassmann, A., and Landgraf, J.: Insights into Tikhonov regularization: application to trace gas column retrieval and the efficient calculation of total column averaging kernels, Atmos. Meas. Tech., 7, 523-535, https://doi.org/10.5194/amt-7-523-2014, 2014.

Borsdorff, T., Aan de Brugh, J., Hu, H., Aben, I., Hasekamp, O., and Landgraf, J.: Measuring Carbon Monoxide With TROPOMI: First Results and a Comparison With ECMWF-IFS Analysis Data, Geophys. Res. Lett., 10, 1769-1767, 2018 a.

Borsdorff, T., aan de Brugh, J., Hu, H., Hasekamp, O., Sussmann, R., Rettinger, M., Hase, F., Gross, J., Schneider, M., Garcia, O., Stremme, W., Grutter, M., Feist, D. G., Arnold, S. G., De Maziére, M., Kumar Sha, M., Pollard, D. F., Kiel, M., Roehl, C., Wennberg, P. O., Toon, G. C., and Landgraf, J.: Mapping carbon monoxide pollution from space down to city scales with daily global coverage, Atmos. Meas. Tech., 11, 5507-5518, https://doi.org/10.5194/amt-11-5507-2018, 2018b.

Borsdorff, T., Andrasec, J., aan de Brugh, J., Hu, H., Aben, I., and Landgraf, J.: Detection of carbon monoxide pollution from cities and wildfires on regional and urban scales: the benefit of CO column retrievals from SCIAMACHY $2.3 \mu \mathrm{m}$ measurements under cloudy conditions, Atmos. Meas. Tech., 11, 2553-2565, https://doi.org/10.5194/amt-11-2553-2018, $2018 \mathrm{c}$. 
Burkholder, J. B., Wine, P. H., Sander, S. P., Abbatt, J. P. D., Huie, R. E., Kurylo, M. J., Wilmouth, D. M., Barker, J. R., Kolb, C. E., and Orkin, V. L.: Chemical Kinetics and Photochemical Data for Use in Atmoshper Studies, Evaluation number 18, Jet Propulsion Laboratorium Publications, Pasadena, California, 2015.

Cusworth, D. H., Mickley, L. J., Sulprizio, M. P., Liu, T., Marlier, M. E., DeFries, R. S., Guttikunda, S. K., and Gupta, P.: Quantifying the influence of agricultural fires in northwest India on urban air pollution in Delhi, India, Environ. Res. Lett., 13, 044018, https://doi.org/10.1088/1748-9326/aab303, 2018.

Dudhia, J.: Numerical Study of Convection Observed during the Winter Monsoon Experiment Using a Mesoscale TwoDimensional Model, J. Atmos. Sci., 46, 3077-3107, 1989.

Ek, M. B., Mitchell, K. E., Lin, Y., Rogers, E., Grunmann, P., Koren, V., Gayno, G., and Tarpley, J. D.: Implementation of Noah land surface model advances in the National Centers for Environmental Prediction operational mesoscale Eta model, J. Geophys. Res., 108, 271-216, 2003.

Ganguly, T.: MoEFCC releases details of National Clean Air Programme; no clarity yet on emission reduction targets, Down to Earth, available at: https://www.downtoearth.org.in/news/moefcc-releases-detailsof-national-clean-air-programme-but-no-clarity-on-emissionreduction-targets-60239, last access: 3 August 2018.

Gani, S., Bhandari, S., Seraj, S., Wang, D. S., Patel, K., Soni, P., Arub, Z., Habib, G., Hildebrandt Ruiz, L., and Apte, J.: Submicron aerosol composition in the world's most polluted megacity: The Delhi Aerosol Supersite campaign, Atmos. Chem. Phys. Discuss., https://doi.org/10.5194/acp-2018-1066, in review, 2018.

Girach, I. A. and Nair, P. R.: Carbon monoxide over Indian region as observed by MOPITT, Atmos. Environ., 99, 599-609, 2014.

Granier, C., Bessagnet, B., Bond, T., D’Angiola, A., van Der Gon, H. D., Frost, G. J., Heil, A., Kaiser, J. W., Kinne, S., Klimont, Z., and Kloster, S.: Evolution of anthropogenic and biomass burning emissions of air pollutants at global and regional scales during the 1980-2010 period, Climatic Change, 109, p. 163, 2011.

Grell, G. A. and Freitas, S. R.: A scale and aerosol aware stochastic convective parameterization for weather and air quality modeling, Atmos. Chem. Phys., 14, 5233-5250, https://doi.org/10.5194/acp-14-5233-2014, 2014.

Grell, G. A., Peckham, S. E., Schmitz, R., McKeen, S. A., Frost, G., Skamarock, W. C., and Eder, B.: Fully coupled "online" chemistry within the WRF model, Atmos. Environ., 39, 6957-6975, 2005.

Guttikunda, S. K. and Gurjar, B. R.: Role of meteorology in seasonality of air pollution in megacity Delhi, India, Environ. Monit. Assess., 184, 3199-3211, 2011.

Huijnen, V., Williams, J., van Weele, M., van Noije, T., Krol, M., Dentener, F., Segers, A., Houweling, S., Peters, W., de Laat, J., Boersma, F., Bergamaschi, P., van Velthoven, P., Le Sager, P., Eskes, H., Alkemade, F., Scheele, R., Nédélec, P., and Pätz, H.-W.: The global chemistry transport model TM5: description and evaluation of the tropospheric chemistry version 3.0, Geosci. Model Dev., 3, 445-473, https://doi.org/10.5194/gmd-3445-2010, 2010.

Huijnen, V., Wooster, M. J., Kaiser, J. W., Gaveau, D. L. A., Flemming, J., Parrington, M., Inness, A., Murdiyarso, D., Main, B., and van Weele, M.: Fire carbon emissions over maritime southeast Asia in 2015 largest since 1997, Sci. Rep., 6, 1-8, 2016.

Janjic, Z. I.: The step-mountain eta coordinate model: Further developments of the convection, viscous sublayer, and turbulence closure schemes, Mon. Weather Rev., 122, 927-945, 1994.

Jha, P. S.: From Field to Fuel, There is an Easy Solution to India's Air Pollution Problem, The WIRE, available at: https://thewire. in/environment/delhi-smog-air-pollution-paddy-burning (last access: 31 July 2018), 2017.

Kan, H., Chen, R., and Tong, S.: Ambient air pollution, climate change, and population health in China, Environ. Int., 42, 10-19, 2012.

KNMI: Validation report of the CAMS near-real time global atmospheric composition service, Tech. Rep., CAMS842015SC3D84.1.1.102017SONv1, KNMI, available at: https://atmosphere.copernicus.eu/sites/default/files/repository/ CAMS84_2015SC3_D84.1.1.10_2017SON_v1_0.pdf, last access: 6 August 2018.

Krol, M., Peters, W., Hooghiemstra, P., George, M., Clerbaux, C., Hurtmans, D., McInerney, D., Sedano, F., Bergamaschi, P., El Hajj, M., Kaiser, J. W., Fisher, D., Yershov, V., and Muller, J.-P.: How much $\mathrm{CO}$ was emitted by the 2010 fires around Moscow?, Atmos. Chem. Phys., 13, 4737-4747, https://doi.org/10.5194/acp-13-4737-2013, 2013.

Krotkov, N. A., McLinden, C. A., Li, C., Lamsal, L. N., Celarier, E. A., Marchenko, S. V., Swartz, W. H., Bucsela, E. J., Joiner, J., Duncan, B. N., Boersma, K. F., Veefkind, J. P., Levelt, P. F., Fioletov, V. E., Dickerson, R. R., He, H., Lu, Z., and Streets, D. G.: Aura OMI observations of regional $\mathrm{SO}_{2}$ and $\mathrm{NO}_{2}$ pollution changes from 2005 to 2015, Atmos. Chem. Phys., 16, 46054629, https://doi.org/10.5194/acp-16-4605-2016, 2016.

Lamarque, J.-F., Bond, T. C., Eyring, V., Granier, C., Heil, A., Klimont, Z., Lee, D., Liousse, C., Mieville, A., Owen, B., Schultz, M. G., Shindell, D., Smith, S. J., Stehfest, E., Van Aardenne, J., Cooper, O. R., Kainuma, M., Mahowald, N., McConnell, J. R., Naik, V., Riahi, K., and van Vuuren, D. P.: Historical (1850-2000) gridded anthropogenic and biomass burning emissions of reactive gases and aerosols: methodology and application, Atmos. Chem. Phys., 10, 7017-7039, https://doi.org/10.5194/acp-10-7017-2010, 2010.

Landgraf, J., aan de Brugh, J., Scheepmaker, R., Borsdorff, T., Hu, H., Houweling, S., Butz, A., Aben, I., and Hasekamp, O.: Carbon monoxide total column retrievals from TROPOMI shortwave infrared measurements, Atmos. Meas. Tech., 9, 49554975, https://doi.org/10.5194/amt-9-4955-2016, 2016.

Liu, T., Marlier, M. E., DeFries, R. S., Westervelt, D. M., Xia, K. R., Fiore, A. M., Mickley, L. J., Cusworth, D. H., and Milly, G.: Seasonal impact of regional outdoor biomass burning on air pollution in three Indian cities Delhi, Bengaluru, and Pune, Atmos. Environ., 172, 83-92, 2018.

Ministry of Environment, Forest and Climate Change (MoEF\&CC): National clean air programme (NCAP)-India, Tech. rep., Ministry of Environment, Forest and Climate Change (MoEF\&CC), Delhi, India, 2018.

Mlawer, E. J., Taubman, S. J., Brown, P. D., Iacono, M. J., and Clough, S. A.: Radiative transfer for inhomogeneous atmospheres: RRTM, a validated correlated-k model for the longwave, J. Geophys. Res.-Atmos., 102, 16663-16682, 1997. 
Mota, B. and Wooster, M. J.: A new top-down approach for directly estimating biomass burning emissions and fuel consumption rates and totals from geostationary satellite fire radiative power (FRP), Remote Sens. Environ., 206, 45-62, 2018.

Spivakovsky, C. M., Logan, J. A., Montzka, S. A., Balkanski, Y. J., Foreman-Fowler, M., Jones, D. B. A., Horowitz, L. W., Fusco, A. C., Brenninkmeijer, C. A. M., Prather, M. J., Wofsy, S. C., and McElroy, M. B.: Three-dimensional climatological distribution of tropospheric $\mathrm{OH}$ : Update and evaluation, Wiley Online Library, 105, 8931-8980, 2000.

Tewari, M., Chen, F., Wang, W., Dudhia, J., LeMone, M. A., Mitchell, K., Ek, M., Gayno, G., Wegiel, J., and Cuenca, R. H.: Implementation and verification of the unified Noah land surface model in the WRF model, in: Conference on Weather Analysis and Forecasting, 11-15 January 2004, 1-6, Seattle, 2004.

Tiwari, S., Bisht, D. S., Srivastava, A. K., Pipal, A. S., Taneja, A., Srivastava, M. K., and Attri, S. D.: Variability in atmospheric particulates and meteorological effects on their mass concentrations over Delhi, India, Atmos. Res., 145-146, 45-56, 2014.

Tiwari, S., Pandithurai, G., Attri, S. D., Srivastava, A. K., Soni, V. K., Bisht, D. S., Kumar, V. A., and Srivastava, M. K.: Aerosol optical properties and their relationship with meteorological parameters during wintertime in Delhi, India, Atmos. Res., 153, 465-479, 2015.

Vadrevu, K. P., Ellicott, E., Badarinath, K. V. S., and Vermote, E.: MODIS derived fire characteristics and aerosol optical depth variations during the agricultural residue burning season, north India, Environ. Pollut., 159, 1560-1569, 2011. van der Gon, H. D., Hendriks, C., Kuenen, J. J. P., Segers, A., and Visschedijk, A. J. H.: Description of current temporal emission patters and sensitivity of predicted AQ for temporal emission patterns, Tech. rep., TNO, Utrecht, the Netherlands, 2011.

van der Werf, G. R., Randerson, J. T., Giglio, L., Collatz, G. J., Mu, M., Kasibhatla, P. S., Morton, D. C., DeFries, R. S., Jin, Y., and van Leeuwen, T. T.: Global fire emissions and the contribution of deforestation, savanna, forest, agricultural, and peat fires (1997-2009), Atmos. Chem. Phys., 10, 11707-11735, https://doi.org/10.5194/acp-10-11707-2010, 2010.

Verma, N., Satsangi, A., Lakhani, A., Kumari, K. M., and Lal, S.: Diurnal, Seasonal, and Vertical Variability in Carbon Monoxide Levels at a Semi-Urban Site in India, CLEAN-Soil Air Water, 45, 1600432, https://doi.org/10.1002/clen.201600432, 2017.

WHO: WHO Global Ambient Air Quality Database (update 2018), available at: http://www.who.int/airpollution/data/cities/en/, last access: 5 November 2018.

Zheng, B., Tong, D., Li, M., Liu, F., Hong, C., Geng, G., Li, H., Li, X., Peng, L., Qi, J., Yan, L., Zhang, Y., Zhao, H., Zheng, Y., He, K., and Zhang, Q.: Trends in China's anthropogenic emissions since 2010 as the consequence of clean air actions, Atmos. Chem. Phys., 18, 14095-14111, https://doi.org/10.5194/acp-18-140952018, 2018. 